\title{
Gender-differences of in vitro colonic motility after chemo- and radiotherapy in humans
}

\author{
Maria Antonietta Maselli ${ }^{1 *}$, Antonia Ignazzi ${ }^{1}$, Francesco Pezzolla², Annunziata Scirocco ${ }^{1}$, Dionigi Lorusso ${ }^{2}$,
} Fabrizio De Ponti ${ }^{3}$ and Carola Severi ${ }^{4}$

\begin{abstract}
Background: The aim of the present in vitro study was to investigate, in different genders, motor responses in surgical colonic specimens from patients with rectal cancer undergoing and not undergoing chemotherapy with capecitabine and radiotherapy.

Methods: This in vitro study was conducted from October 2015 to August 2017 at the Experimental Pharmacology Laboratory at the National Institute "S. de Bellis" after collecting samples at the Department of Surgery. Segments of sigmoid colon were obtained from 15 patients (Male (M)/Female $(F)=8 / 7$; control group, $C G$ ) operated on for elective colorectal resection for rectal cancer without obstruction and 14 patients ( $M / F=7 / 7$; study group, SG) operated on for elective colorectal resection for rectal cancer who also received chemotherapy, based on capecitabine twice daily, and radiotherapy. Isometric tension was measured on colonic circular muscle strips exposed to increasing carbachol or histamine concentrations to obtain concentration-response curves. The motor responses to electrically evoked stimulation were also investigated.
\end{abstract}

Results: In males, carbachol and histamine caused concentration-dependent contractions in the CG and SG. An increased sensitivity and a higher response to carbachol and histamine were observed in SG than CG $(P<0.01)$. On the contrary, in females, the response to carbachol was not significantly different in CG from the SG and the maximal responses to carbachol were greater in $C G$ than in $S G(P<0.001)$. The same applied to histamine for half-maximal effective concentrations and maximal response in that they were not significantly different in CG from the SG. Electrically evoked contractions were significantly more pronounced in males, especially in the SG $(P<0.05)$.

Conclusions: This preliminary in vitro study has shown gender differences in motor responses of colonic circular muscle strips in patients who had received chemotherapy with capecitabine and radiotherapy.

Keywords: Chemotherapy, Radiotherapy, Capecitabine, Carbachol, Histamine, Nitrergic pathways, Motility, Human colon, Gender

\section{Background}

The clinical manifestations associated with exposure to chemotherapy and radiotherapy include diarrhea, abdominal cramps and associated pain and, most frequently, nausea and vomiting $[1,2]$. Diarrhea involves the interaction of motor activity and epithelial transport.

\footnotetext{
* Correspondence: antonella.maselli@irccsdebellis.it

${ }^{1}$ Experimental Pharmacology Laboratory, National Institute of

Gastroenterology "S. de Bellis", Research Hospital - Castellana Grotte (BA),

70013 Castellana Grotte, Italy

Full list of author information is available at the end of the article
}

Mucositis is a key factor to be taken into account after chemo- and radiotherapy [3].

Some authors have shown hypercontractility in gastric fundic and duodenal muscle in rats after exposure to Fluorouracil (5-FU) [4] while others have found increased sensitivity to cholinergic stimulation in the duodenum and colon after whole-body irradiation in guinea pigs $[4,5]$. This increased responsiveness after irradiation may be associated with colonic motor alterations consisting in giant contractions in dogs and intestinal migrating motor complexes disruption in rats $[2,6]$.

(C) The Author(s). 2018 Open Access This article is distributed under the terms of the Creative Commons Attribution 4.0 International License (http://creativecommons.org/licenses/by/4.0/), which permits unrestricted use, distribution, and 
The use of chemo- and radiotherapy disrupts the mucosal barrier and represents a clinically significant risk factor for local infections and sepsis [7]. Some studies demonstrated significant enhancement in gastrointestinal muscle contractility in response to carbachol during infections and chronic inflammation $[8,9]$ and increased sensitivity to histamine in inflammatory conditions related to the release of leukotrienes that increase histamine receptor numbers [10]. Furthermore, the increase in gastrointestinal transit occurring during infection is mediated by endogenous tachykinins, modulated by the activation of nitric oxide (NO) biosynthesis [11]. This tachykinergic component is most probably expressed in elderly male patients per a gender-related difference in receptor density of human colon [12].

Nevertheless, this increased in sensitivity to contractile agonists is not universally observed. For instance, Sung et al. showed a significant reduction in contractility to carbachol in human stomach induced by cisplatin-based chemotherapy [13]. Besides, the response to histamine did not change in colitis in rats [14].

In 5-FU-induced oral mucositis, $\mathrm{NO}$ is also involved. In fact, previous reports showed that proinflammatory cytokines stimulate inducible NO synthase (iNOS)-derived NO production [7]. The NO increase is in agreement with studies reporting increased plasma nitric oxide after oral administration of anticancer drugs in rats and in disagreement with other studies reporting reduced expression of the inducible form of NOS in rats receiving cisplatin and no change in neural NO synthase (nNOS) expression in patients receiving chemotherapy $[13,15,16]$.

These discrepancies in contractile response to agonists, carbachol and histamine, and NO production might be related to differences in species, intestinal tracts, duration of chemotherapy and radiotherapy or length of time after chemo-and radiotherapy as well as to gender.

Possible gender differences in the colonic response to chemotherapy and radiotherapy have not been well characterized. Therefore, the aim of the present in vitro study was to investigate, in different genders, the response to contracting agents (carbachol or histamine) and electrical stimulation in surgical colonic specimens from patients who had undergone standard chemotherapy with capecitabine and radiotherapy, compared to patients who had not undergone chemo- and radiotherapy.

\section{Methods}

This in vitro study was conducted at the Experimental Pharmacology Laboratory of The National Institute of Gastroenterology "S. de Bellis" Castellana Grotte (BA) after collecting samples at the Department of Surgery of the same institute. The in vitro experiments were carried out from October 2015 to August 2017. Segments of sigmoid colon obtained from 15 patients $(\mathrm{M} / \mathrm{F}=8 / 7)$ operated on for elective colorectal resection for rectal cancer served as a control group $(C G)$ and 14 patients $(M / F=7 / 7)$ operated on for elective colorectal resection of rectal cancer who had received neoadjuvant therapy, based on capecitabine (Xeloda ${ }^{\circ}, 825 \mathrm{mg} / \mathrm{m}^{2}$, Welwyn Garden City, United Kingdom), twice daily and one dose of radiotherapy (50.4 Gy in 28 fractions of $180 \mathrm{cGy} /$ die) before surgery served as a study group (SG). Patients were 15 men (8 CG, average age $73.4 \pm 1.1$ years; range $73-76$ years and $7 \mathrm{SG}$, average age $73.3 \pm 1.7$ years; range $72-77$ years) and 14 women (7 CG, average age $74.3 \pm 1.6$ years; range $72-76$ years and $7 \mathrm{SG}$, average age $73.6 \pm 1.3$ years; range $72-78$ years).

In all patients, preanaesthetic medication was intramuscular atropine $(1 \mathrm{mg})$ and midazolam $(5 \mathrm{mg})$. Anaesthesia was induced by propofol $(2.5 \mathrm{mg} / \mathrm{kg})$ intravenously (i.v.) and maintained with nitrous oxide/oxygen $\left(\mathrm{N}_{2} \mathrm{O} / \mathrm{O}_{2}\right)(1 / 2)$ and sevoflurane $(0.5-2 \%)$. Patients received norcuronium $(8 \mathrm{mg})$ i.v. during induction of anaesthesia.

Colonic strips were taken from a carcinoma-free area, $1-4 \mathrm{~cm}$ along the longitudinal axis.

\section{Motility study in vitro}

We used the same methods reported before [17]. In brief, tissues were gently deprived of the mucosa and the muscle segments were cut into strips $(1.0 \mathrm{~cm} \times 0.3 \mathrm{~cm})$ transversely (circular) to the axis of bowel. Circular muscle strips were mounted in an organ bath $(10 \mathrm{ml})$ containing oxygenated Krebs solution, maintained at a temperature of $37^{\circ} \mathrm{C}$ and gassed with $5 \%$ carbon dioxide $\left(\mathrm{CO}_{2}\right)$ in $\mathrm{O}_{2}$. The composition of the Krebs solution was as follows: sodium chloride $(\mathrm{NaCl}) 115.5 \mathrm{mM}$; potassium chloride $(\mathrm{KCl})$ $4.6 \mathrm{mM}$; calcium chloride $\left(\mathrm{CaCl}_{2}\right) 2.5 \mathrm{mM}$; magnesium chloride $\left(\mathrm{MgCl}_{2}\right) 2.1 \mathrm{mM}$; sodium bicarbonate $\left(\mathrm{NaHCO}_{3}\right)$ $21.9 \mathrm{mM}$; monosodium phosphate $\left(\mathrm{NaHPO}_{4}\right) 1.2 \mathrm{mM}$; and glucose $15.5 \mathrm{mM}$. Tissues were stored overnight at $4{ }^{\circ} \mathrm{C}$ prior to use. Strips were tied with a silk ligature to an isometric transducer (Force 100, N. S/N 77648, 77645, 77631, ADInstruments Ltd., Unit B, Bishops Mews, Transport Way, Oxford OX4 6HD, UNITED KINGDOM), and contractions were recorded on a PowerLab/800 (Model ML119 Serial 2265, ADInstruments Ltd., Unit B, Bishops Mews, Transport Way, Oxford OX4 6HD, UNITED KINGDOM) acquisition program. The muscle length was measured directly in the bath by using a caliper. After gentle, repeated washings following by 1 -h stabilization, tissues were placed under a tension of $20-24 \mathrm{mN}$ (in preliminary tests it was shown that this baseline tension produces the maximal response to $1 \times 10^{-6} \mathrm{M}$ carbachol). After equilibration, at least two comparable responses to carbachol were recorded before tissues were exposed to increasing concentrations of carbachol, histamine or electrical field stimulation (EFS). The motor response to carbachol and histamine were investigated on 
circular strips obtained from male and female patients of both groups. Strips were exposed to increasing concentrations of carbachol $\left(1 \times 10^{-8} \mathrm{M}-1 \times 10^{-6} \mathrm{M}\right.$, cumulatively) and histamine $\left(1 \times 10^{-8} \mathrm{M}-1 \times 10^{-6} \mathrm{M}\right.$, cumulatively $)$ in order to obtain concentration-response curves. The curves were repeated after $60 \mathrm{~min}$ and some washing steps.

The motor responses to EFS were investigated on circular strips obtained from male and female patients of both groups. EFS was performed with an electrical stimulator type 215/T (Hugo Sachs Elektronik, March/ Freiburg, Germany) using two platinum wire electrodes (15 $\mathrm{mm}$ in length and $5 \mathrm{~mm}$ in width) placed parallel to the longitudinal axis of the strips. Electrodes were placed $4.5 \mathrm{~mm}$ from the strip. The duration of the train of electrical pulses was always $10 \mathrm{~s}$, and stimulation was performed every $2 \mathrm{~min}(0.1-10 \mathrm{~Hz}$, pulse duration $0.3 \mathrm{~ms}$, supramaximal strength: $20 \mathrm{~V})[18,19]$. The current applied across the bath was monitored and the compliance of voltage was also measured. The time interval between each train of electrical pulses was always $60 \mathrm{~min}$, because preliminary experiments indicated that this allows to evoke reproducible control responses, apart from the first response, which was always discarded. Electrically evoked contractions were evaluated in the presence of atropine $\left(2 \times 10^{-6} \mathrm{M}\right)$, guanethidine $\left(5 \times 10^{-6} \mathrm{M}\right)$ and L-nitro arginine methyl ester (L-NAME $2 \times 10^{-4} \mathrm{M}$ ), an inhibitor of NO synthase. The contact time was $30 \mathrm{~min}$ for atropine and guanethidine and $45 \mathrm{~min}$ for L-NAME. The concentration of atropine was chosen on the basis of previous experiments showing that they fully blocked the contraction produced by $1 \times 10^{-4} \mathrm{M}$ carbachol. The concentration of guanethidine was chosen on the basis of literature data $[20,21]$. At the end of each experiment, strips were removed, blotted, and weighed.

\section{Chemicals}

Carbachol chloride, histamine dihydrochloride, atropine sulphate, guanethidine sulphate, and L-nitro arginine methyl ester (L-NAME) were purchased from Sigma Chemical Co. (St Louis, Missouri, United States). Other chemicals were of the highest quality and were obtained from commercial sources.

\section{Statistical analysis}

The results are given as means \pm standard error (SE) ( $\mathrm{n}$ indicates the number of patients). Carbachol- and histamine-induced contractions were measured as increases over baseline activity and were calculated as $\mathrm{mN}$ per cross sectional area (expressed in $\mathrm{cm}^{2}$ ) $[18,19,22,23]$. We then expressed concentration-response data as a percentage of the maximal response to carbachol or histamine and calculated half-maximal effective concentration $\left(E_{50}\right)$ values with $95 \%$ confidence intervals (CIs) from $\log$ concentration-response curves using non-linear regression analysis. Stress induced by electrical stimulation was expressed as $\mathrm{mN}$ per cross sectional area [18, 19, 22, 23]. We compared data sets with a paired Wilcoxon test (responses before and after treatment), unpaired MannWhitney U test (differences between groups), and unpaired Student's $t$ test, as appropriate. We used a commercial statistical package (GraphPad Prism, version 5 for Windows, GraphPad Software, San Diego, California, United States) and considered statistical significance achieved when $P<0.05$.

\section{Results}

\section{Response to carbachol and histamine}

In male patients, carbachol $\left(1 \times 10^{-8} \mathrm{M}-1 \times 10^{-6} \mathrm{M}\right)$ and histamine $\left(1 \times 10^{-8} \mathrm{M}-1 \times 10^{-6} \mathrm{M}\right)$ caused concentrationdependent contractions in circular muscle strips in the CG and SG (Fig. 1). EC $E_{50}$ values to carbachol were $8.54 \times 10^{-6} \mathrm{M}\left(95 \% \mathrm{CI} 4.54-16.0 \times 10^{-6} \mathrm{M}\right)$ and $1.58 \times$ $10^{-6} \mathrm{M}\left(95 \% \mathrm{CI} 0.68-3.70 \times 10^{-6} \mathrm{M}\right)$ in CG and SG respectively (Fig. 1). This response was greater in SG than in CG $(P<0.01)$. Moreover, the maximal responses to carbachol (expressed in $\mathrm{mN} / \mathrm{cm}^{2}$ ) were significantly higher in SG male patients $\left(4623.0 \pm 894.4 \mathrm{mN} / \mathrm{cm}^{2}\right.$ in SG vs $1621.0 \pm 204.5 \mathrm{mN} / \mathrm{cm}^{2}$ in CG; $\mathrm{P}<0.01$ ).

The same was true when we analyzed histamine-induced responses: $\mathrm{EC}_{50}$ values were $3.77 \times 10^{-6} \mathrm{M}(95 \% \mathrm{CI} 1.79$ $\left.7.94 \times 10^{-6} \mathrm{M}\right)$ and $0.37 \times 10^{-6} \mathrm{M}(95 \%$ CI $0.09-1.42 \times$ $\left.10^{-6} \mathrm{M}\right)$ in CG and SG, respectively. This response was greater in $\mathrm{SG}$ than in CG $(P<0.001)$ (Fig. 2). Again, the maximal responses to histamine were significantly higher in

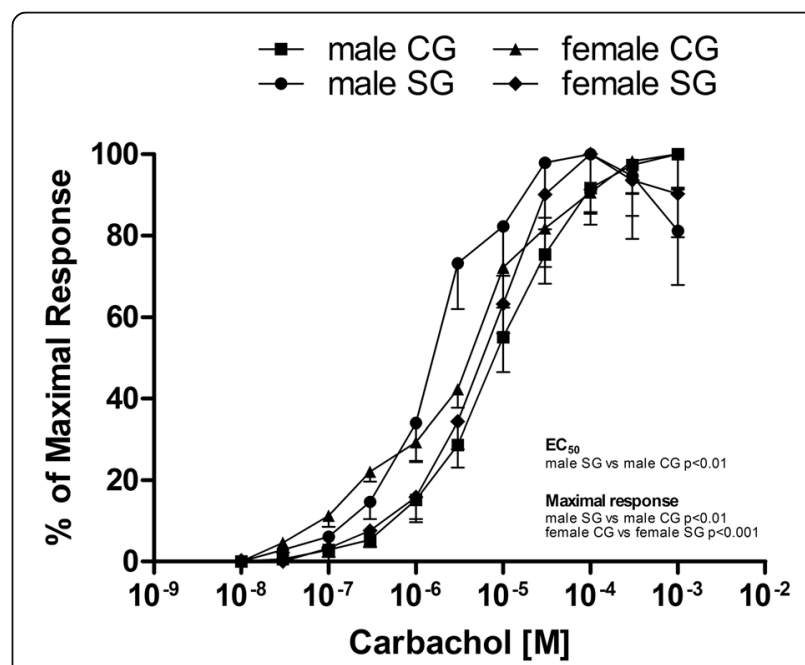

Fig. 1 Log concentration-response curves for carbachol in male and female patients [control group (CG), study group (SG)]. All responses are expressed as a percentage of the control maximal response to carbachol. Results are means \pm standard error (SE) ( $n=15$ male patients and $n=14$ female patients). $P<0.01$, half-maximal effective concentration ( $E_{50}$ ) value in SG male patients vs CG male patients; $P<0.01$, maximal response in SG male patients vs $C G$ male patients; $P<0.001$, maximal response in CG female patients vs SG female patients 


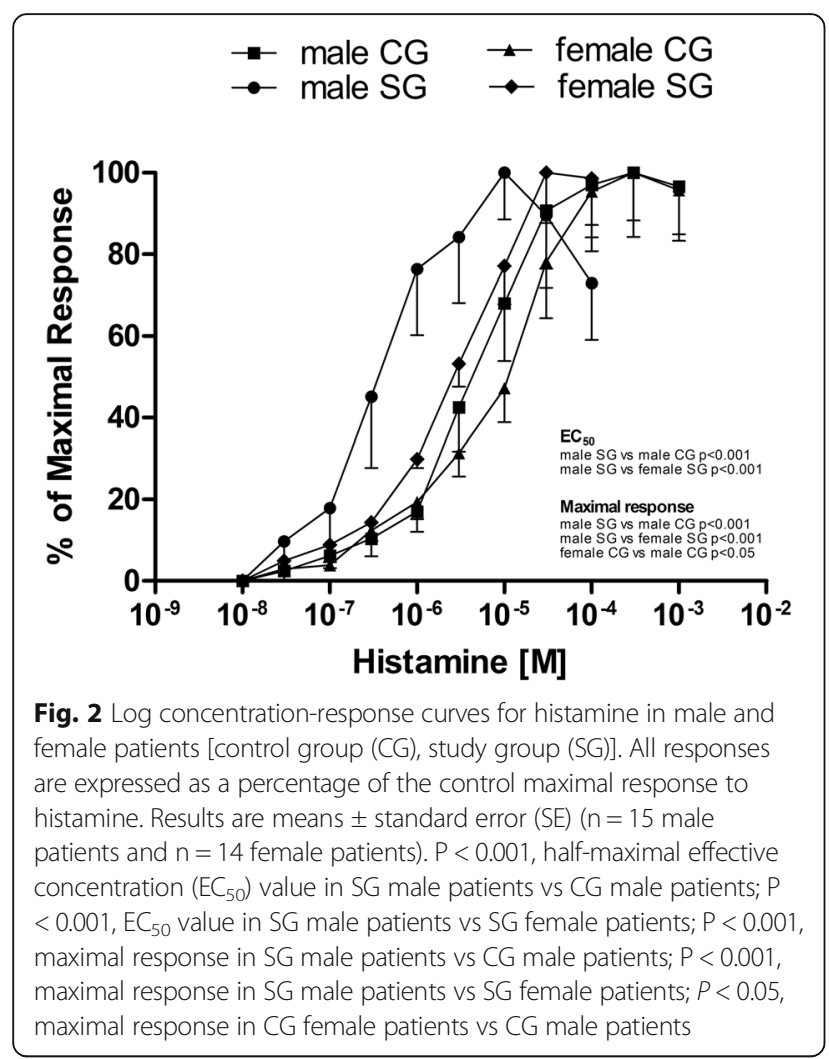

SG male patients $\left(2895.0 \pm 220.0 \mathrm{mN} / \mathrm{cm}^{2}\right.$ in SG vs $847.8 \pm$ $123.9 \mathrm{mN} / \mathrm{cm}^{2}$ in CG; $\mathrm{P}<0.001$ ).

Conversely, in female patients, the response to carbachol $\left(1 \times 10^{-8} \mathrm{M}-1 \times 10^{-6} \mathrm{M}\right)$ was not significantly different in the two groups, with a trend towards a reduced response in SG: $\mathrm{EC}_{50}$ values for carbachol were $3.84 \times$ $10^{-6} \mathrm{M}\left(95 \% \mathrm{CI} 1.85-7.96 \times 10^{-6} \mathrm{M}\right)$ and $6.84 \times 10^{-6} \mathrm{M}$ $\left(95 \%\right.$ CI $\left.3.70-12.63 \times 10^{-6} \mathrm{M}\right)$ in CG and SG, respectively (Fig. 1). The maximal responses to carbachol were significantly higher in CG female patients $(2247.0 \pm 186.9 \mathrm{mN} /$ $\mathrm{cm}^{2}$ in CG vs $1354.0 \pm 109.9 \mathrm{mN} / \mathrm{cm}^{2}$ in SG; $P<0.001$ ).

The response to histamine was not significantly different in the two groups, with a trend towards a reduced response in CG: $\mathrm{EC}_{50}$ values for histamine were $7.99 \times$ $10^{-6} \mathrm{M}\left(95 \% \mathrm{CI} 4.27-14.97 \times 10^{-6} \mathrm{M}\right)$ and $3.85 \times 10^{-6} \mathrm{M}$ $\left(95 \% \mathrm{CI} 2.07-7.14 \times 10^{-6} \mathrm{M}\right)$ in CG and SG, respectively (Fig. 2) and the maximal responses to histamine were not significantly different in the two groups (1384 \pm $154.6 \mathrm{mN} / \mathrm{cm}^{2}$ in CG, $1292.0 \pm 148.7 \mathrm{mN} / \mathrm{cm}^{2}$ in SG).

Moreover, analyzing groups of different gender, in SG maximal responses to carbachol and histamine were significantly more pronounced in male vs female patients $(\mathrm{P}<0.001)$ and $\mathrm{EC}_{50}$ values to histamine were significantly different in male vs female patients $(\mathrm{P}<0.001)$. In CG, the maximal response to histamine was significantly more pronounced in female vs male patients $(P<0.05)$.

\section{Electrically evoked contractions}

In both patient groups, electrically evoked contractions in circular muscle strips were linearly related to stimulation frequency in the $0.1-10 \mathrm{~Hz}$ range: analyzing groups of different gender, electrically evoked contractions were significantly more pronounced in male than in female patients both in CG that in SG at all frequencies.

The contractions in male patients were much more marked in SG than in CG in the $0.3-10 \mathrm{~Hz}$ frequency range (Fig. 3). The same trend was observed in female patients, where electrically evoked contractions were more marked in SG than in CG at frequency $0.1 \mathrm{~Hz}, 1-$ $10 \mathrm{~Hz}$ (Fig. 3).

Analyzing groups of different gender, electrically evoked contractions were significantly more pronounced in male than in female patients both in CG that in SG at all frequencies. In male patients, atropine and guanethidine per se inhibited electrically evoked contractions depending on stimulation frequency. The inhibition was significant in CG at all frequencies and in SG only at 3$10 \mathrm{~Hz}$. The addition of L-NAME reversed atropine and guanethidine inhibition, increasing electrically evoked responses at all frequency in CG and in SG only at 1$3 \mathrm{~Hz}$ (Fig. 4a-b).

In females, also atropine and guanetidine inhibited electrically evoked contractions in CG at all frequency while in SG at the frequency $0.3-10 \mathrm{~Hz}$. As in male patients, the addition of L-NAME reversed atropine and guanetidine inhibition increasing electrically evoked responses in CG







Fig. 4 Electrically evoked contractions in control group (CG) (a) and study group (SG) (b) male patients. CG and SG experiments in the presence of atropine and guanethidine or atropine, guanethidine, and L-nitro arginine methyl ester (L-NAME). Results are means \pm standard error (SE); $\mathbf{a}, \mathrm{n}=8$ patients; $\mathbf{b}, \mathrm{n}=7$ patients. ${ }^{\mathrm{a}} \mathrm{P}<0.05,{ }^{\mathrm{b}} \mathrm{P}<0.01$ and ${ }^{\mathrm{C}} \mathrm{P}<0.001$, atropine and guanethidine vs controls; ${ }^{\mathrm{d}} \mathrm{P}<0.05$ and ${ }^{\mathrm{e}} \mathrm{P}<0.01$, atropine and guanethidine vs atropine, guanethidine, and L-NAME

and in SG, but this was significant at all frequencies only in CG (Fig. 5a-b).

Notably, the effect of L-NAME was most marked in CG males and less pronounced in SG males, CG and SG females.

\section{Discussion}

In this study, in vitro colonic motor responses to carbachol, histamine or electrical stimulation after chemoand radiotherapy were quite different in male and female patients. Some of the observed gender differences were so remarkable that in our opinion they deserve a preliminary report here, since they are also in line with circumstantial evidence already available in the literature. However, we must acknowledge important intrinsic limitations of our study: we could analyse only a limited number of surgical specimens, which did not allow us to further investigate mechanisms underlying the gender differences. Furthermore, we cannot completely rule out the possibility that at least some of the observed differences might be due to heterogeneity of the clinical condition in individual patients.

Colonic circular muscle strips after chemo- and radiotherapy in SG were more sensitive to carbachol and histamine with respect to controls in males. Sensitivity to carbachol in these patients is in line with previous findings showing hypercontractility in gastric fundic and duodenal muscle, in both inflammatory and post-inflammatory phases of 5-FU induced intestinal mucositis in rats [4]. Other authors showed increased sensitivity to cholinergic stimulation in the duodenum and colon after whole-body irradiation in guinea pigs [5]. This increased responsiveness may be associated with colonic motor alterations consisting in giant contractions in dogs and intestinal migrating motor complexes disruption in rats $[2,6]$. The increased incidence of giant contractions has been
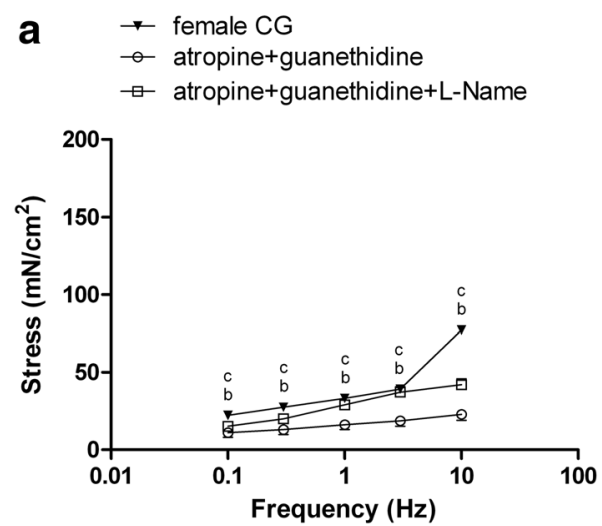
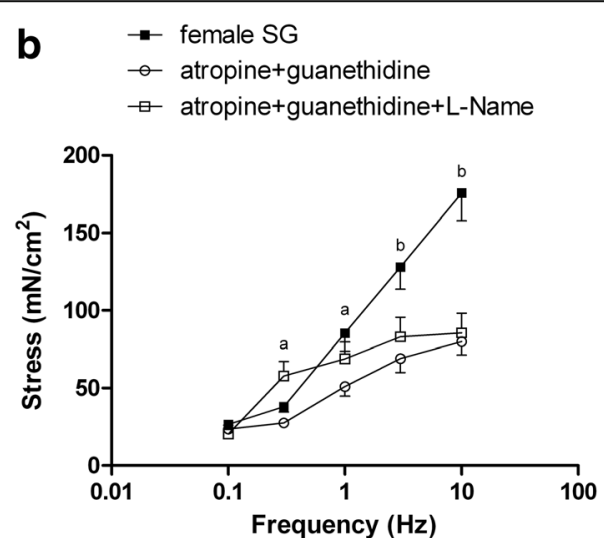

Fig. 5 Electrically evoked contractions in control group (CG) (a) and study group (SG) (b) female patients. CG and SG experiments in the presence of atropine and guanethidine or atropine, guanethidine, and L-NAME. Results are means \pm standard error (SE); $\mathbf{a}, \mathrm{n}=7 \mathrm{patients,} \mathbf{b}, \mathrm{n}=7$ patients. ${ }^{\mathrm{a}} \mathrm{P}<0.05$ and ${ }^{b} \mathrm{P}<0.01$, atropine and guanethidine vs controls; ${ }^{c} \mathrm{P}<0.05$, atropine and guanethidine vs atropine, guanethidine, and L-NAME 
suggested to be responsible for the iatrogenic side effects such as diarrhea, abdominal cramping and vomiting $[2,6,24]$. Furthermore, other studies have demonstrated significant enhancement in gastrointestinal muscle contractility in response to carbachol during chronic inflammation and infections $[8,9]$. When the mucosal barrier is damaged, the use of chemo- and radiotherapy represents a risk factor for local infections and sepsis [7].

Increased sensitivity to histamine has also been reported in inflammatory conditions related to the release of leukotrienes enhancing histamine receptor numbers [10]. Nevertheless, this increased sensitivity to contractile agonists is somewhat controversial. Sung et al. showed significantly reduced contractility to carbachol in human stomach after cisplatin-based chemotherapy [13]. Besides, the response to histamine did not change in colitis in rats [14]. These discrepancies might be related to differences in species, intestinal tracts, duration of chemotherapy or length of time after chemotherapy as well as to gender.

In the present study, the sensitivity and the maximum response to carbachol or histamine were greater in male than in female SG patients. Even considering the mean age of our patients, this different response might at least in part be ascribed to female hormones, although we cannot rule out other factors. Indeed, Kaur et al. [25] showed increased estrogen levels after surgery even in postmenopausal women. This may be an indicator than under stress (as after chemo- and radiotherapy) estrogen levels can be higher even in postmenopausal women. Therefore the different responses that we observed might be relative to an effect of female hormones still released under stress. An alternative explanation is that gender differences might be ascribed to the fact that in postmenopausal women tissues, in any case, have been exposed to estrogens in previous years, so that, even when oestrogen levels decrease, tissue responses may still differ. Interestingly, ovariectomy in adult female rabbits caused altered receptor sensitivity and increased intrinsic smooth muscle sensitivity to histamine in vascular smooth muscle. This would further explain the genderdependent difference that we observed in females compared to males [26].

In the CG, we confirm the data previously published in our recent study on elderly female and male patients, where females were more sensitive and showed higher maximal response to carbachol [17]. These observations are in line with previous findings, one showing increased response to carbachol in animals, while the other suggested that aging induces an increase in Calcium ions $\left(\mathrm{Ca}^{2+}\right)$ store with consequent $\mathrm{Ca}^{2+}$ overload, although these data do not specifically refer to gender differences $[27,28]$.

Also electrically evoked contractions were more marked in SG than in CG in both genders and this may be due to the formation of peroxynitrite. During severe inflammation, as observed after 5-FU treatment, a generation of reactive oxygen species (ROS) occurs. ROS directly damage cells, tissues, blood vessels and stimulate transcriptions factors, such as nuclear transcription factor-kB (NF-kB), which in turn causes up-regulation of pro-inflammatory cytokines, such as interleukin-1(IL-1), interleukin-6 (IL-6) and tumor necrosis factor alpha (TNF-alfa). Previous reports show that 5-FU induces oral mucositis causing proinflammatory cytokines that stimulate iNOS-derived NO production [7]. The reaction between $\mathrm{NO}$ and ROS produces peroxynitrite, a toxic compound that causes lipid peroxidation, oxidation of protein sulfhydryl groups, with tissue injury and local increase of inflammation [7, 29, 30].The increased electrically evoked contraction could also be attributed to tachykininergic components. The increase in gastrointestinal transit occurring during infection is mediated by endogenous tachykinins, which are modulated by the activation of NO biosynthesis [11]. This tachykininergic component is most probably expressed in elderly male patients. In fact, Burcher et al. showed a gender-related difference in receptor density of human colon, with binding capacity $\left(\mathrm{B}_{\max }\right)$ lower in females than in males [12]. An increase in $\mathrm{NO}$ is in agreement with reports of an increased plasma nitric oxide after oral administration of anticancer drugs in rats and in disagreement with other reports of a reduced expression of the inducible form of NOS in rats receiving cisplatin and of no change in neural NO synthase (nNOS) expression in patients receiving chemotherapy $[13,15,16]$.

It is difficult to explain why the electrically evoked contractile response were greater in males than in females after chemo- and radiotherapy. However, even in the control group, the response to electrical stimulation is greater in males than in females, as we have already shown in previous work [17]. Besides, the response to EFS and L-NAME was lower in females than in males both in CG and in SG, possibly because elderly females are not under the influence of female hormones unlike adult females, as suggested in our previous study [17].

One study hypothesized that advanced age is associated with decreased expression of neuronal NO synthase (nNOS) and concomitant reduction in synthesis of $\mathrm{NO}$ in rat colon [31]. That may contribute to explain our findings in females. Other studies showed that estrogens increase endothelial NO synthase (eNOS) [32, 33], but inhibit iNOS [32]. During inflammatory reactions, NO levels, produced by iNOS, increase and this may contribute to local tissue damage [34-37]. This may explain the lack of difference in response to L-NAME group SG in both genders.

In order to explain the increased sensitivity to carbachol and decreased response to EFS and L-NAME in CG female 
patients we hypothesize a decreased expression of nNOS with concomitant reduction in synthesis of NO [31].

\section{Conclusions}

This preliminary in vitro study indicates gender differences in the motor responses of colonic circular muscle strips exposed to cholinergic, histaminergic and electrical stimulation in patients who have received chemotherapy with capecitabine and radiotherapy. Further studies to elucidate the underlying mechanisms are warranted.

\section{Abbrevations}

5-FU: Fluorouracil; EFS: Electrically evoked stimulation; eNOS: Endothelia nitric oxide synthase; IL-1: interleukin-1; IL-6: interleukin-6; iNOS: inducible nitric oxide synthase; L-NAME: L-nitro arginine methyl ester; NF-kB: nuclear transcription factor-kB; nNOS: neuronal nitric oxide synthase; NO: nitric oxide; ROS: reactive oxygen species; TNF-alfa: tumor necrosis factor alpha; M: Male; F: Female; SE: standard error; $\mathrm{N}_{2} \mathrm{O} / \mathrm{O}_{2}$ : nitrous oxide/oxygen; $\mathrm{B}_{\text {max }}$ : binding capacity; Cl: confidence interval; $\mathrm{Ca}^{2+}$ : Calcium ions; i.v.: intravenous

\section{Acknowledgements}

We wish to thank Dr. Maria Lucia Caruso for her collaboration as a pathologist

\section{Author contributions}

All authors have reviewed the manuscript for its scientific content and approved its final version. MAM designed the study and drafted the manuscript; Al performed the experiments on muscle strips and analyzed the data; DL contributed to patients' selection, provided surgical specimens and contributed to data collection; FP contributed to patients' selection, provided surgical specimens and contributed to data collection; AS contributed to data analysis; FDP contributed to data analysis and interpretation and reviewed the draft of the manuscript; CS designed the study and drafted the manuscript.

\section{Funding}

The project was funded by the Italian Ministry of Health through Grant RO 06.17. The Italian Ministry of Health had no role in the design of the study, collection, analysis, and interpretation of data or in writing the manuscript.

\section{Availability of data and materials}

The datasets used and analysed during the current study are available from the corresponding author on reasonable request.

\section{Ethics approval and consent to participate}

The study was reviewed and approved by the Ethics Committee of the National Cancer Research Center, IRCCS Oncologico Giovanni Paolo II, Bari, Italy. Written informed consent was obtained from all participants.

\section{Consent for publication}

Not applicable.

\section{Competing interests}

The authors declare that they have no competing interests.

\section{Publisher's Note}

Springer Nature remains neutral with regard to jurisdictional claims in published maps and institutional affiliations.

\section{Author details}

${ }^{1}$ Experimental Pharmacology Laboratory, National Institute of Gastroenterology "S. de Bellis", Research Hospital - Castellana Grotte (BA), 70013 Castellana Grotte, Italy. ${ }^{2}$ Department of Surgery, National Institute of Gastroenterology "S. de Bellis", Research Hospital - Castellana Grotte (BA), 70013 Castellana Grotte, Italy. 'Department of Medical and Surgical Sciences, University of Bologna, 40126 Bologna, Italy. ${ }^{4}$ Department of Internal Medicine and Medical Specialities, University Sapienza, 00161 Rome, Italy.
Received: 2 October 2017 Accepted: 17 July 2018

Published online: 03 August 2018

\section{References}

1. Riezzo G, Clemente C, Leo S, Russo F. The role of electrogastrography and gastrointestinal hormones in chemotherapy-related dyspeptic symptoms. J Gastroenterol. 2005:40(12):1107-15.

2. Picard C, Wysocki J, Fioramonti J, Griffiths NM. Intestinal and colonic motor alterations associated with irradiation-induced diarrhoea in rats. Neurogastroenterol Mot. 2001;13(1):19-26

3. Lockhart PB, Sonis ST. Alterations in the oral mucosa caused by chemotherapeutic agents. A histologic study. J Dermatol Surg Oncol. 1981; 7(12):1019-25.

4. Soares PM, Mota JM, Gomes AS, Oliveira RB, Assreuy AM, Brito GA, Santos AA, Ribeiro RA, Souza MH. Gastrointestinal dysmotility in 5-fluorouracilinduced intestinal mucositis outlasts inflammatory process resolution. Cancer Chemother Pharmacol. 2008;63(1):91-8.

5. Krantis A, Rana K, Harding RK. The effects of $\gamma$-radiation on intestinal motor activity and faecal pellet expulsion in the Guinea pig. Dig Dis Sci. 1996; 41(12):2307-16

6. Summers RW, Hayek B. Changes in colonic motility following abdominal irradiation in dogs. Am J Phys. 1993;264(6 Pt 1):G1024-30.

7. Leitão RF, Ribeiro RA, Bellaguarda EA, Macedo FD, Silva LR, Oriá RB, Vale ML, Cunha FQ, Brito GA. Role of nitric oxide on pathogenesis of 5-fluorouracil induced experimental oral mucositis in hamster. Cancer Chemother Pharmacol. 2007:59(5):603-12.

8. Moreels TG, De Man JG, Bogers JJ, De Winter BY, Vrolix G, Herman AG, Van Marck EA, Pelckmans PA. Effect of Schistosoma mansoni-induced granulomatous inflammation on murine gastrointestinal motility. Am J Physiol Gastrointest Liver Physiol. 2001;280(5):G1030-42.

9. Vermillion DL, Collins SM. Increased responsiveness of jejunal longitudinal muscle in Trichinella-infected rats. Am J Phys. 1988;254(1 Pt 1):G124-9.

10. Pynaert G, Grooten J, van Deventer SJ, Peppelenbosch MP. Cysteinyl leukotrienes mediate histamine hypersensitivity ex vivo by increasing histamine receptor numbers. Mol Med. 1999:5(10):685-92

11. Martínez-Cuesta MA, Barrachina MD, Beltrán B, Calatayud S, Esplugues J. Nitric oxide modulates the acute increase of gastrointestinal transit induced by endotoxin in rats: a possible role for tachykinins. J Pharm Pharmacol. 1997:49(10):988-90

12. Burcher E, Shang F, Warner FJ, Du Q, Lubowski DZ, King DW, Liu L. Tachykinin NK2 receptor and functional mechanisms in human colon: changes with indomethacin and in diverticular disease and ulcerative colitis. J Pharmacol Exp Ther. 2008;324(1):170-8.

13. Sung EZ, Arasaradnam RP, Jarvie EM, James S, Goodyear SJ, Borman RA Snead D, Sanger GJ, Nwokolo CU. Effects of neo-adjuvant chemotherapy for oesophago-gastric cancer on neuro-muscular gastric function. Mol Biol Rep. 2012:39(12):9989-94

14. Wells RW, Blennerhassett MG. Persistent and selective effects of inflammation on smooth muscle cell contractility in rat colitis. Pflugers Arch. 2004:448(5):515-24.

15. Nagahama S, Korenaga D, Honda M, Inutsuka S, Sugimachi K. Assessment of the intestinal permeability after a gastrectomy and the oral administration or anticancer drugs in rats: nitric oxide release in response to gut injury. Surgery. 2002;131(1 Suppl):S92-7.

16. Wang Y, Aggarwal SK. Effects of cisplatin and taxol on inducible nitric oxide synthase, gastrin and somatostatin in gastrointestinal toxicity. Anti-Cancer Drugs. 1997:8(9):853-8.

17. Maselli MA, Trisolini P, Demma I, Pezzolla F, De Ponti F. Gender- and agerelated differences in muscular and nerve-mediated responses in human colon. Dig Dis Sci. 2011;56(2):352-8.

18. Snape WJ Jr, Williams R, Hyman PE. Defect colonic smooth muscle contraction in patients with ulcerative colitis. Am J Phys. 1991;261(6 Pt 1):G987-91.

19. Snape WJ Jr, Kim BH, Willenbucher R, Koelbel CB, Mayer EA Jr, Walsh JH. Differences in the response of proximal and distal rabbit colonic muscle after electrical field stimulation. Gastroenterology. 1989:96(2 Pt 1):321-6.

20. Takeuchi T, Niioka S, Yamaji M, Okishio Y, Ishii T, Nishio H, Takatsuji K, Hata F. Decrease in participation of nitric oxide in nonadrenergic, noncholinergic relaxation of rat intestine with age. Jpn J Pharmacol. 1998;78(3):293-302.

21. Mitolo-Chieppa D, Mansi G, Rinaldi R, Montagnani M, Potenza MA, Genualdo M, Serio M, Mitolo Cl, Rinaldi M, Altomare DF, Memeo V. 
Cholinergic stimulation and nonadrenergic, noncholinergic relaxation of human colonic circular muscle in idiopathic chronic constipation. Dig Dis Sci. 1998;43(12):2719-26.

22. Snape WJ Jr, Mayer EA, Koelbel CB, Hyman PE, Williams R, Root D. Response of smooth muscle from proximal and distal human colon. Neurogastroenterol Motil. 1989;1:29-34.

23. Maselli MA, Piepoli AL, Guerra V, Caruso ML, Pezzolla F, Lorusso D, Demma I, De Ponti F. Colonic smooth muscle responses in patients with diverticular disease of the colon: effect of the NK2 receptor antagonist SR48968. Dig Liver Dis. 2004;36(5):348-54.

24. Otterson MF, Sarna SK, Moulder JE. Effects of fractionated doses of ionizing radiation on small intestinal motor activity. Gastroenterology. 1998;95(5): 1249-57.

25. Kaur G, Mishra S, Kaur A, Sehgal A, Nageswari KS, Prasad R. Retention of ovaries and oxidative stress of surgery. Int I Gynaecol Obstet. 2007;97(1):40-3.

26. Ma L, Yu Z, Xiao S, Thadani U, Robinson CP, Patterson E. Supersensitivity to serotonin- and histamine-induced arterial contraction following ovariectomy. Eur J Pharmacol. 1998 Oct 23;359(2-3):191-200.

27. Zhang L. Muscarinic receptors in developing rat colon. Eur J Pharmacol. 1996;304(1-3):211-9.

28. Lopes GS, Ferreira AT, Oshiro ME, Vladimirova I, Jurkiewicz NH, Jurkiewicz A, Smaili SS. Aging-related changes of intracellular $\mathrm{Ca}^{2+}$ stores and contractile response of intestinal smooth muscle. Exp Gerontol. 2006;41(1):55-62.

29. Rubbo H, Radi R, Trujillo M, Telleri R, Kalyanaraman B, Barnes S, Kirk M, Freeman BA. Nitric oxide regulation of superoxide and peroxynitritedependent lipid peroxidation. Formation of novel nitrogen-containing oxidized lipid derivatives. J Biol Chem. 1994;269(42):26066-75.

30. Radi R, Beckman JS, Bush KM, Freeman BA. Peroxynitrite oxidation of sulfhydryls. The cytotoxic potential of superoxide and nitric oxide. J Biol Chem. 1991;266(7):4244-50

31. Takahashi T, Qoubaitary A, Owyang C, Wiley JW. Decreased expression of nitric oxide synthase in the colonic myenteric plexus of age rats. Brain Res. 2000;883(1):15-21.

32. Orshal JM, Khalil RA. Gender, sex hormones, and vascular tone. Am J Physiol Regul Integr Comp Physiol. 2004;286(2):R233-49.

33. Tostes RC, Nigro D, Fortes ZB, Carvalho MH. Effects of estrogen on the vascular system. Braz J Med Biol Res. 2003;36(9):1143-58.

34. Ajuebor MN, Virág L, Flower RJ, Perretti M, Szabó C. Role of inducible nitric oxide synthase in the regulation of neutrophil migration in zymosaninduced inflammation. Immunology. 1998;95(4):625-30.

35. Brenner T, Brocke S, Szafer F, Sobel RA, Parkinson JF, Perez DH, Steinman L. Inhibition of nitric oxide synthase for treatment of experimental autoimmune encephalomyelitis. J Immunol. 1997;158(6):2940-6.

36. Hierholzer C, Harbrecht B, Menezes JM, Kane J, MacMicking J, Nathan CF, Peitzman AB, Billiar TR, Tweardy DJ. Essential role of induced nitric oxide in the initiation of the inflammatory response after hemorrhagic shock. J Exp Med. 1998;187(6):917-28

37. Lohinai Z, Benedek P, Fehér E, Györfi A, Rosivall L, Fazekas A, Salzman AL, Szabó C. Protective effects of mercaptoethylguanidine, a selective inhibitor of inducible nitric oxide synthase, in ligature-induced periodontitis in the rat. Br J Pharmacol. 1998;123(3):353-60.

Ready to submit your research? Choose BMC and benefit from:

- fast, convenient online submission

- thorough peer review by experienced researchers in your field

- rapid publication on acceptance

- support for research data, including large and complex data types

- gold Open Access which fosters wider collaboration and increased citations

- maximum visibility for your research: over $100 \mathrm{M}$ website views per year

At BMC, research is always in progress.

Learn more biomedcentral.com/submissions 